\title{
Bone marrow-derived cells and the vasculature in diabetes: from biomarker to treatment?
}

\author{
N. A. Hanley
}

Received: 25 June 2007 / Accepted: 27 June 2007 / Published online: 26 July 2007

(C) Springer-Verlag 2007

In early June 2007, a search for 'stem cells' and 'diabetes' in PubMed retrieved 549 articles. The breakdown was rather skewed: 497 were published after the year 2000, whilst a mere 52 were published earlier. This difference largely reflects the first description of human embryonic stem cells (ESCs) in 1998 [1]. Nearly a decade has passed since then, and stem cell research has diversified. Human ESCs for engineering transplantable beta cells ex vivo have attracted great interest in both the commercial and academic sectors, but have yet to deliver in the clinic - a timeline of which we should perhaps be proud, given the need for ESCderived therapy to be as least as safe and effective as exogenous insulin therapy. However, pluripotency, the ability of a precursor to turn into many different cell types, has undoubtedly raised public, government and academic awareness of a much broader area of research. Clinicians may feel some cynicism at the thought of transplanting beta cells produced ex vivo from ESCs to achieve injection-free, safe, curative therapy, but the concept of regenerative medicinegrowing back missing cells, organs and tissues by reawakening differentiation from endogenous precursors - has been taken up with renewed optimism [2,3]. Whatever one's opinion, the research and the debate have proved exciting, and a significant proportion has been played out in Diabetologia [4-11].

Stem cell or regenerative therapy in diabetes extends beyond making beta cells. It has been observed that

N. A. Hanley

Centre for Human Development, Stem Cells \& Regeneration,

University of Southampton, Southampton General Hospital,

Southampton, UK

N. A. Hanley ( $\bowtie)$

Human Genetics Division, Southampton General Hospital,

Duthie Building, Mailpoint 808, Tremona Road,

Southampton SO16 6YD UK

e-mail: N.A.Hanley@soton.ac.uk autologous haematopoietic stem cell transplantation can alleviate immune destruction in new-onset type 1 diabetes [12], and bone marrow-derived (BMD) cells downstream of their founder stem cell population have been recognised to serve as endothelial progenitor cells (EPCs). EPCs raise the prospect of extending replacement or regeneration to the treatment of diabetic vascular complications. Even so, the EPC remains controversial: What is its phenotype? What does it signify? and, most presciently, What does it do? Detailed answers to these questions will be important, since intervention has the potential to repair vascular endothelium injured within the diabetic milieu. On an observational level, measuring EPC numbers in peripheral blood may offer a readily accessible, independent biomarker of cardiovascular risk [13]. This research is broadly applicable and promising, yet in getting to grips with the EPC, one encounters the first problem: it means different things to different people. In 1997, approximately 1 year before the first derivation of human ESCs, Ashihara and colleagues reported the presence of BMD endothelial cell precursors in the human adult circulation [14]. The cells were identified from expression on their cell surface of cluster of differentiation (CD) 34, a sialomucin-like adhesion molecule, and the vascular endothelial growth factor receptor 2 (VEGFR2, also called kinase insert domain receptor [KDR]), which transduces the potent angiogenic signal of VEGF. However, this phenotype almost certainly identifies a heterogeneous cell population. As is frequently problematic in cell biology, the antigens are not unique, a feature that has led some of the original authors to advocate type 3 nitric oxide synthase as a better marker of EPC phenotype [15]. Functional assays increase the rigour of characterisation. The clonogenic capacity to form new vessels in in vitro culture is an attractive method to define the true potency of these progenitors in greater detail [16]. However, as with ESC differentiation, or indeed, ascribing the fate of any cell in a dish, appearances 
can be deceptive, especially without strict lineage tracing by indelible markers. Does a row of coalesced cells in an apparent tube-like structure really represent a new blood vessel? Did it arise solely from the presumed EPCs? Concern deepens if one or two surface antigens are found that were not expected, for example CD1a and CD45 [15]. Like a blood vessel, but not quite a blood vessel-does it matter? Thus, assessments have been made of whether EPCs integrate into vessels in vivo. Putting to one side the confounding risk of cell fusion, an expanding body of evidence supports a contribution of circulating BMD cells to new vessel formation in living animal models. So, by considering these independent studies together, can we gain greater confidence as to the nature of BMD cells typed for a few carefully selected cell surface antigens? The answer is probably yes, which is good, because it is inconceivable that we could apply the increasingly strict 'entry requirements' of EPC status to all research. In particular, association studies of large cohorts do not lend themselves practically (and financially) to in vitro characterisation of vessel-forming capacity in all participants, much less to assessment in vivo in animal models. In these circumstances, it seems practicable to use the label EPC based on cell surface antigens, but it must be clearly apparent which ones have been investigated. CD34, CD133 and VEGFR2 are those that are commonly referenced [16].

Low numbers of circulating CD $34^{+} /$VEGFR $2^{+}$cells, or $\mathrm{CD}_{133^{+}}$cells, have been reported as a positive predictor of future cardiovascular events in a cohort of patients with cardiac vessel disease proven by angiography [17], giving rise to enthusiastic debate. Sub-acute or acute coronary events may confound EPC assessment, since inflammation has major effects on the recruitment of a wide range of bone marrow cells into the circulation. Furthermore, if total circulating cell populations vary, proportional changes could occur in an EPC sub-fraction without alteration in their absolute number. Fluorescence-activated cell sorting also has technical intricacies that may affect results and their interpretation, as recently came to light for invariant natural killer cells and asthma [18, 19]. Conversely, in support of a predictive link between EPCs and cardiovascular risk, the number of circulating EPCs rises with statin therapy, mirroring improvements in other 'established' cardiovascular risk factors [20].

In this issue of Diabetologia, Fadini and colleagues make an association between circulating EPC numbers and glucose tolerance in non-diabetic individuals [21], extending previous data from the same authors on circulating EPC numbers in diabetes as a barometer of cardiovascular risk $[22,23]$. Recognising that glucose tolerance is a continuum between values in the normal range and in diabetes, the results are not necessarily surprising, yet they are important as we seek to identify and intervene earlier to help patients at risk of cardiovascular disease. It is not clear why participants were attending a metabolic screening clinic and why the mean age was different between the control and study groups. However, putting these issues aside, the glucose status of all participants was characterised by fasting analysis and glucose tolerance test, and correlated with peripheral blood samples analysed for $\mathrm{CD}_{3} 4^{+} /$ VEGFR2 $^{+}$cell counts. The study showed that $\mathrm{CD} 34^{+}$and $\mathrm{CD} 34^{+} / \mathrm{VEGFR}^{+}$counts were negatively correlated with both fasting and post-challenge blood glucose [21]. In a previous study by the authors, diminution of the number of cells carrying the same surface markers correlated with peripheral vascular disease in diabetic individuals [24]. However, the broader picture is rather more complex, as others have found that EPC numbers in diabetic individuals fluctuate with glycaemic control [25], implying that risk calculation in any one patient will need to include parameters such as $\mathrm{HbA}_{1 \mathrm{c}}$.

Association data such as these can give rise to new hypotheses on causation and potentially lead to new interventional therapies. Applying this model to EPCs and diabetes supports the rationale for using BMD cells in the repair of injured endothelium as a regenerative attempt to improve vascular function and blood flow in ischaemic territories [16]. BMD cells appear to contribute to the upkeep of the vasculature in adulthood, although the percentage of cells incorporated into the vessel wall is small and varies from organ to organ and across studies [15]. Yet the extrapolation from physiology to pathology is not straightforward. In hypoxia or in response to intimal damage, the proportion of BMD cells in the peripheral circulation rises, tempting mechanistic speculation on tissue repair [15]. Supplementing this process to actively treat diabetic vascular complications by BMD cell infusions and/ or by the application of vascularisation factors, such as VEGF or possibly stomal cell-derived factor-1 (SDF1) the chemokine ligand for the receptor, chemokine (C-X-C motif) receptor 4 (CXCR4), would be attractive as a means of recruiting new vessels into ischaemic areas of the heart and/or peripheral vasculature. Nevertheless, great caution is clearly warranted. New therapies bring with them new side effects. To date, clinical trials using BMD cells following myocardial infarction or cardiac failure have reported on small cohorts with short follow-up times [26]; overly simplistically but nevertheless of concern, tumour growth also depends on angiogenesis; and stimulating new vessels risks aggravating diabetic microvascular complications such as retinopathy. To accompany these rather obvious considerations, there are more subtle ones. Infused EPCs may not function well in poorly perfused tissues, as has been shown for EPCs from obese diabetic mice, thus losing the vessel-forming capacity that was apparent under the standardised conditions of the laboratory culture dish [27]. 
Furthermore, in applying a heterogeneous BMD population to achieve a homogeneous EPC effect, some cells may potentially aggravate inflammation.

In summary, the concept of easily accessible, circulating cells as independent biomarkers of cardiovascular risk is an exciting development. To interpret this risk accurately, there is an urgent need for us to reach unified agreement on EPC identity to allow isolation and better characterisation. Stratifying risk accurately in the clinical situation will also require detailed attention to individual levels of glycaemic control. At present, we are only just beginning to appreciate the complexity and significance of the EPC. Whilst recognising that exciting times may lie ahead for interventional studies, caution is needed if we are to avoid premature judgements on success or failure. As a specialty, we are currently in debate over a drug that has been commonly prescribed in recent years [28, 29]; perhaps because they are so exciting, the utmost care and attention is needed to ensure that pioneering cellular therapies do not return to haunt us in years to come.

Acknowledgements N. A. Hanley receives funding from the Wellcome Trust in partnership with the Juvenile Diabetes Research Foundation, the Engineering and Physical Sciences Research Council (EPSRC) and the Biotechnology and Biological Research Council (BBSRC).

\section{References}

1. Thomson JA, Itskovitz-Eldor J, Shapiro SS et al (1998) Embryonic stem cell lines derived from human blastocysts. Science 282:1145-1147

2. Meier JJ, Bhushan A, Butler AE, Rizza RA, Butler PC (2005) Sustained beta cell apoptosis in patients with long-standing type 1 diabetes: indirect evidence for islet regeneration? Diabetologia 48:2221-2228

3. Meier JJ, Lin JC, Butler AE, Galasso R, Martinez DS, Butler PC (2006) Direct evidence of attempted beta cell regeneration in an 89 -year-old patient with recent-onset type 1 diabetes. Diabetologia 49:1838-1844

4. Atkinson MA, Rhodes CJ (2005) Pancreatic regeneration in type 1 diabetes: dreams on a deserted islet? Diabetologia 48:2200 2202

5. Leon-Quinto T, Jones J, Skoudy A, Burcin M, Soria B (2004) In vitro directed differentiation of mouse embryonic stem cells into insulin-producing cells. Diabetologia 47:1442-1451

6. Piper K, Ball SG, Turnpenny LW, Brickwood S, Wilson DI, Hanley NA (2002) Beta-cell differentiation during human development does not rely on nestin-positive precursors: implications for stem cell-derived replacement therapy. Diabetologia 45:10451047

7. Rolletschek A, Kania G, Wobus AM (2006) Generation of pancreatic insulin-producing cells from embryonic stem cells-'proof of principle', but questions still unanswered. Diabetologia 49:25412545

8. Serup P (2006) Embryonic stem cell-based diabetes therapy-a long road to travel. Diabetologia 49:2537-2540
9. Shim JH, Kim SE, Woo DH et al (2007) Directed differentiation of human embryonic stem cells towards a pancreatic cell fate. Diabetologia 50:1228-1238

10. Sipione S, Eshpeter A, Lyon JG, Korbutt GS, Bleackley RC (2004) Insulin expressing cells from differentiated embryonic stem cells are not beta cells. Diabetologia 47:499-508

11. Soria B, Skoudy A, Martin F (2001) From stem cells to beta cells: new strategies in cell therapy of diabetes mellitus. Diabetologia 44:407-415

12. Voltarelli JC, Couri CE, Stracieri AB et al (2007) Autologous nonmyeloablative hematopoietic stem cell transplantation in newly diagnosed type 1 diabetes mellitus. JAMA 297:1568-1576

13. Hill JM, Zalos G, Halcox JP et al (2003) Circulating endothelial progenitor cells, vascular function, and cardiovascular risk. New Engl J Med 348:593-600

14. Asahara T, Murohara T, Sullivan A et al (1997) Isolation of putative progenitor endothelial cells for angiogenesis. Science 275:964-967

15. Schatteman GC, Dunnwald M, Jiao C (2007) Biology of bone marrow-derived endothelial cell precursors. Am J Physiol 292: $\mathrm{H} 1-\mathrm{H} 18$

16. Rafii S, Lyden D (2003) Therapeutic stem and progenitor cell transplantation for organ vascularization and regeneration. Nat Med 9:702-712

17. Werner N, Kosiol S, Schiegl T et al (2005) Circulating endothelial progenitor cells and cardiovascular outcomes. New Engl J Med 353:999-1007

18. Akbari O, Faul JL, Hoyte EG et al (2006) CD4+ invariant T-cellreceptor+ natural killer T cells in bronchial asthma. New Engl J Med 354:1117-1129

19. Vijayanand P, Seumois G, Pickard C et al (2007) Invariant natural killer T cells in asthma and chronic obstructive pulmonary disease. New Engl J Med 356:1410-1422

20. Walter DH, Zeiher AM, Dimmeler S (2004) Effects of statins on endothelium and their contribution to neovascularization by mobilization of endothelial progenitor cells. Coron Artery Dis 15:235-242

21. Fadini GP, Pucci L, Vanacore R et al (2007) Glucose tolerance is negatively associated with circulating progenitor cell levels. Diabetologia DOI 10.1007/s00125-007-0732-y

22. Fadini GP, Miorin M, Facco M et al (2005) Circulating endothelial progenitor cells are reduced in peripheral vascular complications of type 2 diabetes mellitus. J Am Coll Cardiol 45:1449-1457

23. Fadini GP, Sartore S, Albiero M et al (2006) Number and function of endothelial progenitor cells as a marker of severity for diabetic vasculopathy. Arterioscler Thromb Vasc Biol 26:2140-2146

24. Fadini GP, Sartore S, Baesso I et al (2006) Endothelial progenitor cells and the diabetic paradox. Diabetes Care 29:714-716

25. Humpert PM, Neuwirth R, Battista MJ et al (2005) SDF-1 genotype influences insulin-dependent mobilization of adult progenitor cells in type 2 diabetes. Diabetes Care 28:934-936

26. Bartunek J, Vanderheyden M, Wijns W et al (2007) Bone-marrowderived cells for cardiac stem cell therapy: safe or still under scrutiny? Nature Clinical Practice Cardiovascular Medicine (Suppl 1):S100-S105

27. Awad O, Jiao C, Ma N, Dunnwald M, Schatteman GC (2005) Obese diabetic mouse environment differentially affects primitive and monocytic endothelial cell progenitors. Stem Cells 23:575-583

28. Nissen SE, Wolski K (2007) Effect of rosiglitazone on the risk of myocardial infarction and death from cardiovascular causes. New Engl J Med 356:2457-2471

29. Drazen JM, Morrissey S, Curfman GD (2007) Rosiglitazonecontinued uncertainty about safety. New Engl J Med DOI 10.1056/NEJme078118 